\title{
Reconstruir algún orden en el caos. Problemas del cirujano COVID
}

\author{
Reconstructing some order in chaos. Problems of the COVID surgeon
}

\author{
Alberto Campos*
}

\author{
*Correspondencia: Dr. Alberto Campos \\ E-mail: alberto_campos@hotmail.com \\ https://orcid.org/0000-0001-5811-1908
}

\begin{abstract}
Palabras clave: COVID-19, cirugía, lista de verificación, evidencia, recomendaciones.

Keywords: COVID-19, surgery, surgical safety checklist, evidence, recommendations.
\end{abstract}

\section{RESUMEN}

Este artículo trata el caos del cirujano y los varios problemas que enfrenta ante la pandemia de COVID-19. Aborda varios problemas. Uno, que las controversias médicas se han convertido en disputas y políticas públicas a base de ocurrencias, omisiones y retóricas de Estado. Dos, cómo el exceso de información - de calidad heterogénea e incompleta, de miles de publicaciones de estudios mal hechos, de conflictos de lógica entre metodología y conclusiones y de resultados falsos o fraudulentos - es difícil de procesar y produce saturación y confusión. Finalmente, se discute el papel de la experiencia práctica, de las recomendaciones y de los criterios que cada cirujano deberá asumir para encontrar un orden personal en el caos.

\section{ABSTRACT}

This article deals with the surgeon's chaos and several problems opposite the COVID-19 pandemic. It addresses several problems. One, medical controversies have turned into disputes and public policies based on occurrences, omissions, and rhetorics of the State. Two, how the excess of information -of heterogeneous and incomplete quality, from thousands of publications of poorly made studies with conflicts of logic between methodology and conclusions, and false or fraudulent results - is difficult to process and produces saturation and confusion. Finally, the role of practical experience, recommendations, and criteria each surgeon must assume to find a personal order in chaos is discussed.

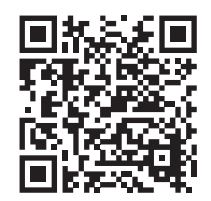

Cualquier intento de organizar la ciencia de revista en un todo unificado encontraría pronto numerosas dificultades. [...] La ciencia de revista lleva, por tanto, el sello de lo provisional y lo personal. [...] Si se entiende por hecho sólo lo fijo y demostrado, entonces éste existe sólo en la ciencia de manual. (Ludwik Fleck, 1935) $^{1}$

\section{CONTROVERSIAS CIENTÍFICAS}

$\mathrm{L}^{\mathrm{a}}$ a ciencia avanza mediante controversias que surgen de la publicación de resultados experimentales y observacionales. Sin embargo, la carga de la prueba puede estar sujeta a un refinamiento técnico e instrumental y a evidencia todavía no disponible en algún momento de la controversia. ${ }^{2}$
Todo es provisional en la ciencia de revista. En el mejor caso es producto del consenso de algunos expertos. En esta pandemia de COVID-19 nada es todavía ciencia fija, de manual o de libro. ${ }^{1}$

Qué hipótesis pueden mantenerse como hechos científicos, la calidad de las pruebas, la replicación de los experimentos, los mecanismos de arbitraje y las revisiones por pares, todo es controversial. ${ }^{3}$ Sobre todo, se requieren tiempos largos para su confirmación o refutación.

\section{POLÉMICAS, POLÍTICAS PÚBLICAS, OCURRENCIAS Y SERENDIPIAS}

Cuando las controversias médicas salen a la luz pública el desorden argumental se contamina con opiniones de quienes no entienden

Citar como: Campos A. Reconstruir algún orden en el caos. Problemas del cirujano COVID. Cir Gen. 2020; 42(2): 176-181. doi: 10.35366/95378 
la investigación científica, ni cómo opera, ni sus limitaciones. Hay un hiato entre lo que "dicen" los estudios y lo que interpretan los funcionarios que instrumentan políticas de salud pública.

Sin comprender las publicaciones especializadas, sin conocimiento de fondo para enfrentar el desafío epistémico, con mixturas de creencias incoherentes e incluso pensamiento mágico e intereses diversos, convierten controversias en disputas de todo tipo.

Los enredos, que pudieron solucionarse con previsión y prudencia, se han convertido en retóricas de funcionarios para diluir la percepción pública del problema, para no crear alarma, en vez de conformar recomendaciones generales coherentes.

Gobernantes y funcionarios han diseñado políticas contradictorias, entre vacilaciones y ocurrencias con poco sustento, del rigor obligatorio a lo optativo, que no pueden ser ni lo uno ni lo otro sin haber tomado previsiones de respaldo económico y social para una población mayoritaria en situación de pobreza y pobreza extrema.

Esa mayoría, fuerza de trabajo sin educación, sin seguridad social ni acceso a servicios de salud ${ }^{4}$ —antes insuficientes y ahora saturados- no puede entenderlas ni acatarlas.

El paternalismo de iluminados aumenta la confusión general cuando varios funcionarios todavía aparecen en conferencias de prensa y eventos masivos sin protección, unidos en una inmunidad de rebaño ideológico que tampoco es inmune al contagio. Disociar los discursos de las acciones es enviar un doble mensaje que confunde.

Los conflictos de interés entre asesores financieros y de salud pública tendrán un impacto social muy grave. La disputa sobre privilegiar la salud o la economía es un "falso dilema". La reapertura apresurada habrá producido mayores casos, decesos y daños económicos, ${ }^{5}$ un yerro muy costoso que tendrá un efecto búmeran durante años. ${ }^{6,7}$

En tal conflicto de intereses y desidias añejas, los trabajadores de la salud, ignorados o abastecidos mínimamente, además de comprar insumos con recursos propios han tenido que fabricar y reciclar mascarillas y equipo de protección personal (EPP) con serendipias diversas, desde lavarlos hasta hornearlos. ${ }^{8,9}$ Ante el riesgo y políticas deficientes hay que improvisar. Aquí cabe el proverbio "adaptarse o morir".

\section{EL TSUNAMI DE INFORMACIÓN}

La información sobre la transmisión, el contagio del SARS-CoV-2 y la enfermedad multisistémica que produce se ha convertido en pocos meses en un "tsunami de artículos", más de 5,000 por semana, 31,000 a fines de mayo, 52,000 a mediados de junio de 2020, imposibles de escrutar y evaluar a pesar de herramientas de inteligencia artificial (IA) creadas ex profeso. ${ }^{10}$ Se publican en línea antes de revisión por pares, con alguna advertencia de "publicación en línea" [Epub ahead of print] o "borrador" [pre-proof], en un esfuerzo de rápida divulgación cuya desventaja es el enorme volumen.

Existe una base de datos COVID-19 de investigación abierta (COVID-19 Open Research Dataset, CORD-19) que incluye más de 128,000 artículos revisados por pares y preimpresiones, además de estudios previos sobre coronavirus. ${ }^{11}$ Hay también un Nuevo Centro de Recursos Coronavirus (Novel Coronavirus Information Center) de acceso abierto a investigaciones y noticias publicadas por Elsevier. ${ }^{12}$

Los problemas con tal cantidad de información son varios; la falta de tiempo para leerlos, la dificultad de separar el oro de la escoria, el que un $20 \%$ de ellos no es gratuito y menos de un $50 \%$ provee el texto completo. Buena parte de la literatura es inaccesible a los médicos o programas de IA.

Por otra parte, los algoritmos de IA no siempre son exactos y la calidad de lo publicado es heterogénea; la mayoría son sólo comentarios, o modelos y protocolos de mala calidad. Los médicos han preferido recurrir a los métodos tradicionales, boletines de diferentes sociedades, revistas con gran tradición y prestigio y la recomendación de boca en boca. ${ }^{10}$

El valor de las tecnologías de la información radica en que pueden sosegar la discordancia entre creencias viejas e información nueva que produce ansiedad. ${ }^{13}$ Pero mucho de la literatura en línea carece de calidad, y hay que 
agregar la enorme cantidad de pseudociencia que prolifera en lenguaje sencillo, convincente y atractivo no sólo para los enfermos, sino también para el médico incauto.

No es imposible que el médico sienta la tentación de tomar atajos y cortar esquinas en sus análisis. La capacidad de pensamiento crítico afecta el modo como actuamos con la tecnología "inteligente". Teléfonos y computadoras pueden servir como un "segundo cerebro" para aligerar el pensamiento, pero pueden afectar, para mal, nuestra voluntad de creer y nuestra visión de mundo. ${ }^{14}$ Ser médico no supone ser inmune a la basura intelectual.

En el caos hay reglas que vale la pena recordar; la regla 80/20, erróneamente llamada Principio de Pareto, reformulada por Juran como de "lo poco vital y lo mucho trivial."15 O la ley de Sturgeon, que estipula que "nada es siempre absolutamente así, [que] noventa por ciento de todo es porquería". (Crud [mi traducción]). ${ }^{16}$

Hay, desde hace años, otra pandemia, el "morbus fraudulentus". ${ }^{17}$ Un artículo publicado es un artículo publicado. Diga lo que diga engorda revistas y currículos con mierda difícil de verificar. La mierda, sin eufemismos ni comillas, ha aumentado y se disemina con las tecnologías de la comunicación. ${ }^{18,19}$

Daniel Dennett advierte sobre el uso de "profundeces" (deepities [mi traducción]) que a primera vista son "manifiestamente falsas, pero serían cruciales si fueran ciertas [o por otra parte], son verdaderas pero triviales". ${ }^{20}$ (Cursivas mías.) Para desecharlas se precisa inteligencia, conocimiento de fondo, habilidad para detectar conflictos entre la validez lógica de la metodología de un estudio y sus conclusiones y, sobre todo, la disposición de analizar a conciencia lo que se lee.

Hay que mencionar también los conversatorios en línea, que han proliferado hasta la saturación. Tienen varias limitaciones; ritmos lentos, consumen más horas comparados con procesos de selección de la literatura, puede haber varios en un día y se invierte tiempo en recibir información de calidad desigual y redundante, puesto que todos abrevamos casi de las mismas fuentes. Los mismos temas y opiniones, recurrentes, también saturan.

\section{EVIDENCIA, EXPERIENCIA, CRITERIOS, CONSENSOS Y RECOMENDACIONES}

Cuando la evidencia es escasa, se produce despacio, o la información es tan extensa que rebasa la capacidad humana, la experiencia gana valor. El Colegio Americano de Cirujanos $^{21}$ ha emitido recomendaciones sobre la cancelación o priorización de procedimientos electivos. Pero la Sociedad Americana de Cirujanos Gastrointestinales y Endoscópicos (Society of American Gastrointestinal and Endoscopic Surgeons, SAGES) especifica en su página que "no son guías formales, y que debido a limitaciones de tiempo no han sido revisadas ni autentificadas utilizando procesos rigurosos estándar". ${ }^{22}$ (Cursivas mías.)

A pesar de la recomendación de hacer pruebas serológicas rápidas a todo candidato a intervención quirúrgica y —-más aún- con regularidad, a todos los trabajadores de la salud, no sólo para la protección a la que tienen derecho, sino para evaluar qué hospitales pudieren trabajar "libres" [sic] de COVID, ${ }^{23-25}$ en México se han desestimado con la justificación de que son poco sensibles y que "no existe conexión técnica, científica, lógica, automática entre el número de pruebas y el éxito del control". [sic ${ }^{26}$

Ya se han documentado infecciones asintomáticas en trabajadores de la salud en Bélgica y el Reino Unido, aún con máscaras y EPP. En el primer estudio, la mayoría que dio positivo a lgG (75\%) recordaba haber tenido síntomas previos; los más comunes, anosmia, fiebre y tos. ${ }^{27} \mathrm{En}$ el otro estudio, todos los que habían trabajado en áreas COVID dieron positivo al análisis de genoma viral, pero también el $66 \%$ de quienes trabajaban en unidades "NO-COVID". $[s i c]^{28}$

Los retos incluyen el aumento de la capacidad de pruebas diagnósticas, problemas logísticos en hospitales públicos, los tiempos de rotación del personal y la disminución de la fuerza de trabajo si un buen número de ellos resultase positivo. ${ }^{28}$ Pero si la ausencia de evidencia no es evidencia de ausencia, entonces una prueba poco sensible es más sensible que ninguna prueba. Médicos y pacientes se infectan mutuamente, y tanto los pacientes hospitalizados como los trabajadores de la salud deben ser considerados población en riesgo. 
En pleno pico del contagio el cirujano -que no es epidemiólogo acostumbrado a mecanismos, dispositivos y protocolos de protección que no funcionan si no son usados de manera correcta, y para los cuales nunca fue entrenado- se enfrenta a situaciones desconocidas. Las epidemias recientes, limitadas a regiones distantes, eran atendidas por otros.

Antes de pensar en la cirugía electiva, fuente de sus ingresos, y aun cuando emocionalmente su cabeza esté en cómo ha de sobrevivir a la recesión que vendrá, tiene que pensar, racionalmente, cómo no contagiarse en el mar de virus y perderlo todo. 'Todo' puede significar no sólo sus ingresos, sino su vida. Para ello debe primero adiestrarse y dominar las técnicas de EPP y los protocolos de movimientos en el quirófano.

Hay recomendaciones y protocolos, listas de verificación para la seguridad del cirujano COVID surgidos de organizaciones internacionales. ${ }^{29-31}$ Algunas asociaciones nacionales han emitido algoritmos, políticas y procedimientos pertinentes, ${ }^{32}$ pero no todos los hospitales tienen las capacidades económicas para su cumplimiento. Cada equipo tendrá que adecuarse a la falta de previsión nacional, a un proceso de ensayo y error y a su curva de aprendizaje.

No estoy diciendo que sea fácil, y menos en una situación catastrófica, digo que una adaptación adecuada implica el ejercicio deliberado de postergar algunas emociones. Los humanos no somos aristotélicamente "racionales por naturaleza" sino, como ha sido demostrado, malos procesadores de información. Para mantener la estabilidad emocional somos reacios a los cambios y justificamos nuestras creencias e intuiciones. ${ }^{33-35}$

Juzgar a la ligera y sacar conclusiones rápidas es eficiente cuando es probable que estas sean correctas, nos ahorren tiempo y los costos de un posible error sean aceptables. Pero el juicio ligero es riesgoso cuando la situación es incierta, lo que está en juego es grave y hay poco tiempo para recolectar y procesar información. En esas circunstancias, los errores intuitivos pueden impedirse mediante un análisis racional, deliberado, pensando lentamente. ${ }^{36}$

\section{EL EFECTO RASHOMON}

En este escenario se presenta el efecto Rashomon, que deriva del cuento En el bosque, en el que Ryunosuke Akutagawa ${ }^{37}$ relata un asesinato desde varios testimonios diferentes, incluyendo el del muerto (a través de un médium), y deja al lector la tarea de construir conclusiones, sin saber bien a bien qué pasó.

De un Estado fallido, con desorden administrativo, con políticas surgidas de la inmediatez del conteo deficiente de defunciones diarias, un sistema de salud colapsado y sin coordinación para proveer insumos indispensables con la calidad apropiada, menos todavía para establecer normas, y con retóricas redundantes, el cirujano no puede esperar nada más que un efecto Rashomon.

\section{FICCIONES ÚTILES}

Es un hecho que en el gremio hay cirujanos deficientes en lingua franca, que recurren solamente a información en español. Es natural que algunos esperen una guía o Norma Oficial Mexicana (NOM) sobre cualquier aspecto relacionado con COVID-19 — del rastreo a los protocolos, a lo que se quiera-que puede tardar años y no estar exenta de ser incomprensible. ${ }^{38}$

¿Qué puede hacerse? Asumir realidades poco conocidas y disfrazarlas como ficciones útiles, como hipótesis provisionales. Ya en la edad media se conocían como fictio rationis, instrumentos necesarios para ciertas formas de razonar, situaciones que asumimos "como si", como si fueran ciertas, como realidades hipotéticas.

$\mathrm{Y}$ aquí lo interesante; en la incertidumbre no puede decirse que "son", pero tampoco puede decirse que "no son". Pueden ser usadas "con conciencia de su falsedad, pero a la vez [mientras se reúne la evidencia suficiente] con conciencia de su fecundidad". ${ }^{39}$ (Cursivas mías.)

Una ficción útil como regla de oro, es asumir que "todo paciente (y todo territorio hospitalario) es COVID positivo mientras no se demuestre lo contrario". De ella dependerá la propia seguridad.

Asumir que todo es COVID positivo implica destrezas y medidas adaptativas contra la ineficiencia y el abandono del Estado. Hay tres, 
la resiliencia, esa capacidad de recuperación frente a una situación adversa; la creatividad, esa imaginación constante para resolver problemas prácticos, y la cooperación solidaria, lo único que paliará la orfandad de un Estado que no cumple su contrato social.

\section{UNA PARADOJA EN EL CAOS}

Una paradoja aproxima dos ideas opuestas y en apariencia irreconciliables, pero con una "profunda y sorprendente coherencia en su sentido figurado". ${ }^{40}$

Son paradojas dos citas de Heráclito de Éfeso, trilladas y acaso poco pensadas. Su fragmento 12 dice "a cualquiera que entre a un mismo río le fluyen siempre aguas diferentes". El fragmento 6 dice que el sol "no es nuevo cada día, sino continuamente nuevo". ${ }^{41,42}$

Si conectamos estos fragmentos con el epígrafe de Fleck es fácil darnos cuenta de lo inútil de perseguir lo fijo. Todo lo vivo es cambiante, salvo nuestra voluntad terca de buscar y querer vivir certezas.

En este inicio de pandemia, a pesar de la solidaridad gremial — que no de las instituciones públicas - cada cirujano está, paradójicamente, solo frente al caos. No sólo el cirujano académico, docente, también el cirujano común, para quien la cirugía era simplemente un modo de ganarse la vida. Para adaptarse deberá tomar decisiones prácticas, con base en heurísticas y criterios propios no exentos de error. ${ }^{33-35}$

Es fácil entonces ver de nuevo el problema —bien tangible, nada filosófico-, el hiato entre la evidencia y la experiencia. Cada cirujano enfrentará el reto de establecer sus mejores prácticas.

Para sobrevivir el caos general cada cirujano deberá construir su orden personal.

\section{REFERENCIAS}

1. Fleck L. Entstehung und Entwicklung einer wissenschaftlichen Tatsache. Einführung in die Lehre vom Denkstil un Denkkollektiv. Frankfurt del Meno: Suhrkamp Verlag, 1980, del original editado en Basilea: Benno Schwabe, 1935. Se cita de la v.e. La génesis y el desarrollo de un hecho científico. Introducción a la teoría del estilo de pensamiento y del colectivo de pensamiento. Madrid: Alianza, 1986. p. 166-172.
2. Dascal M. Epistemología, controversias y pragmática. Isegoría. 1995; (12): 8-43. doi.org/10.3989/ isegoria.1995.i12

3. Kitcher P. Patterns of Scientific Controversies. En: Machamer P, Pera M y Baltas A (eds.) Scientific Controversies: philosophical and historical perspectives. Nueva York; Oxford University Press, 2000. p. 21-39.

4. Hernández-Licona G. Lineamientos y criterios generales para la definición, identificación y medición de la pobreza. Diario Oficial de la Federación (DOF), [Internet] Ciudad de México, 2018, oct. 30. Disponible en: http://dof.gob.mx/nota_detalle.php?codigo $=554$ $2421 \&$ fecha $=30 / 10 / 2018$ [Consulta del 21 de mayo de 2020].

5. Gurría A. La crisis del covid-19: recomendaciones para México. Nexos. 2020; 42 (511): 16-19. Disponible en: https://impresa.nexos.com.mx/ (Publicado en línea, el 1 de julio de 2020) [Consulta del 1 de julio de 2020].

6. Green ST. Cassandra's curse and covid-19: why do governments listen to businesses over doctors? BMJ 2020; 369: m1852. doi.org/10.1136/bmj.m1852 (Publicado el 13 de mayo de 2020) [Consulta del 7 de junio de 2020].

7. Garrett L. The world knows an apocalyptic pandemic is coming — but nobody is interested in doing anything about it. Foreign Policy. Septiembre 20 de 2019. Disponible en: https://foreignpolicy.com/2019/09/20/ the-world-knows-an-apocalyptic-pandemic-iscoming/ [Consulta del 21 de mayo de 2020].

8. Mackenzie D. Reuse of N95 masks. Engineering 2020. doi.org/10.1016/j.eng.2020.04.003. (Publicado en línea, el 13 de abril de 2020) [Consulta del 7 de junio de 2020].

9. Rimmer A. COVID-19: experts question guidance to reuse PPE. BMJ 2020; 369: $\mathrm{m} 1577$.

10. Brainard J. New tools aim to tame pandemic paper tsunami. Science 2020; 368 (6494): 924-925. doi. org/10.1126/science.368.6494.924

11. Open Research Dataset (CORD-19). Disponible en: https://cord19.aws/ [Consulta del 29 de mayo de 2020].

12. Elsevier. Novel Coronavirus Information Center. Disponible en: https://www.elsevier.com/connect/ coronavirus-information-center [Consulta del 30 de junio de 2020].

13. Festinger L. Cognitive dissonance. Scientific American 1962; 207 (4): 93-107. doi.org/10.1038/ scientificamerican1062-93

14. Pennycook G et al. Everyday consequences of analytic thinking. Current Directions in Psychological Science. 2010; 24 (6): 425-432. doi. org/10.1177/0963721415604610

15. Juran JM. The non-Pareto Principle; mea culpa. Selected Papers 1975; (18): 1-3. doi.org/10.1.1.521. 6224\&rep $=$ rep $1 \&$ type $=$ pdf

16. Sturgeon T. On hand: a book. Venture Science Fiction, 1957; 1 (5): 49. En: Oxford English Dictionary, Science fiction citations. Disponible en: https://www. jessesword.com/sf/view/328 (Publicado en línea, el 30 de julio de 2010) [Consulta del 21 de junio de 2020].

17. Black M. The prevalence of humbug. Philosophic Exchange 1982; 13 (1): 1-25. Disponible en: http:// digitalcommons.brockport.edu/phil_ex/vol13/iss1/4 
18. Pennycook $G$ et al. On the reception and detection of pseudo-profound bullshit. Judgment and Decision Making 2015; 10 (6): 549-563. Disponible en: http:// journal.sjdm.org/15/15923a/jdm15923a.pdf

19. Frankfurt HG. On Bullshit. Princeton: Princeton University Press, 2005.

20. Dennett DC. A dozen general thinking tools. En: Intuition pumps and other tools for thinking. Nueva York: W. W. Norton \& Company; 2013. p. 24-61. (V.e.: Bombas de intuición y otras herramientas de pensamiento. (tr. Laura Lecuona) Ciudad de México: Fondo de Cultura Económica; 2015)

21. American College of Surgeons (ACS). COVID-19: Guidance for Triage of Non-Emergent Surgical Procedures. En línea: marzo 24, 2020, actualización del 27 de marzo. Disponible en: https://www.facs. org/-/media/files/covid19/guidance for triage of nonemergent_surgical_procedures.ashx $x$. [C̄onsultā dē 21 de junio de 2020].

22. Society of American Gastrointestinal and Endoscopic Surgeons (SAGES). SAGES COVID-19 / Coronavirus Announcement Archives. Disponible en: https://www. sages.org/category/covid-19/ [Consulta del 21 de junio de 2020].

23. Centers for Disease Control and Prevention (CDC). Interim Guidelines for COVID-19 Antibody Testing in Clinical and Public Health Settings. En línea: 23 de mayo de 2020. Diponible en: https://www.cdc.gov/ coronavirus/2019-ncov/lab/resources/antibody-testsguidelines.html [Consulta del $1^{\circ}$ de junio de 2020].

24. Centers for Disease Control and Prevention (CDC). Testing for COVID-19. En línea: 24 de junio de 2020. Disponible en: https://www.cdc.gov/coronavirus/2019ncov/symptoms-testing/testing.html [Consulta del 26 de junio de 2020].

25. Royal College of Surgeons of England. Survey findings: Elective surgery during COVID-19. En línea: 26 de junio de 2020. Disponible en https://www.rcseng. ac.uk/news-and-events/news/archive/survey-resultselective-surgery-under-covid/ [Consulta del 27 de junio de 2020].

26. Agencia EFE. Aplicar más pruebas no garantiza control de COVID-19, dice autoridad de Salud. En línea: 11 de junio de 2020. Disponible en: https://www.msn. com/es-us/news/other/aplicar-m-c3-a1s-pruebas-nogarantiza-control-de-covid-19-dice-autoridad-de-salud/ ar-BB15jWFu . [Consulta del 11 de junio de 2020].

27. Steensels D et al. Hospital-wide SARS-CoV-2 antibody screening in 3056 staff in a tertiary center in Belgium. JAMA 2020 Jun 15; [e-pub]. Disponible en: https:// doi.org/10.1001/jama.2020.11160. [Consulta del 1 de julio de 2020].
28. Rivett $L$ et al. Screening of healthcare workers for SARS-CoV-2 highlights the role of asymptomatic carriage in COVID-19 transmission. eLife 2020 May 11; 9:e58728. Disponible en: https://doi. org/10.7554/eLife.58728 [Consulta del 11 de mayo de 2020].

29. Wax RS, Christian MD. Practical recommendations for critical care and anesthesiology teams caring for novel coronavirus (2019-nCoV) patients. Can J Anesth/J Can Anesth. 2020; (67): 568-576. doi.org/10.1007/ s12630-020-01591-x

30. Ti LK, Ang LS, Foong TW et al. What we do when a COVID-19 patient needs an operation: operating room preparation and guidance. Can J Anesth/J Can Anesth. 2020; (67): 756-758. doi.org/0.1007/s12630020-01617-4

31. Centers for Disease Control and Prevention (CDC). Sequence for putting on personal protective equipment (PPE) https://www.cdc.gov/niosh/npptl/pdfs/PPESequence-508.pdf [Consulta del 3 de junio de 2020].

32. Hospital Español de Veracruz. Protocolos y Políticas Covid-19. Disponible en: https://heveracruz.mx/ protocolos-y-politicas-covid-19/ [Consulta del 6 de junio de 2020].

33. Kahneman D. Judgment and decision making: a personal view. Psychological Science. 1991; (2): 142145.

34. Tversky A, Kahneman D. Judgment under uncertainty: Heuristics and biases. Science. 1974; 185 (4157): 1124-1131. doi.org/10.1126/science.185.4157.1124.

35. Tversky A, Kahneman D. The framing of decisions and the psychology of choice. Science. 1981; 211 (4481): 453-458. doi.org/10.1126/science.7455683

36. Kahneman D. A machine for jumping to conclusions. En: Thinking, fast and slow. Nueva York, Farrar, Straus and Giroux, 2011. p. 79-89.

37. Akutagawa R. En el bosque. En: Rashōmon y otros cuentos. (Tr. José Kozer). Madrid, Miraguano Ediciones, 1987. p. 29-45.

38. Campos A. Las narrativas de la normatividad quirúrgica. ¿Realidad o ficción? Cir Gen. 2020; 42 (1): 69-83. dx.doi.org/10.35366/92715

39. Ferrater-Mora J. Diccionario de filosofía. ( 5 a ed.) Buenos Aires: Ed. Sudamericana, 1964. p. 651-652.

40. Beristáin H. Diccionario de retórica y poética. (7a ed.) Ciudad de México: Ed. Porrúa, 1995. p. 380.

41. Heráclito de Éfeso. En: Diels H. Fragmenter der Vorsokratiker. (2a ed.) Vol. 1. Berlín: Weidmannsche Buchhandlung, 1906. p. 62-64.

42. Heráclito de Éfeso. En: Mondolfo R. Heráclito. Textos y problemas de su interpretación. (13 ${ }^{\mathrm{a}}$ ed.) Siglo XXI editores. México, 2007. p. 31-32. 